\title{
1 Quantitative and Qualitative Analysis of Biodiesel by NMR Spectroscopic Methods
}

\section{Author: Khalid I Doudin}

3 Address: Chemical Engineering and Applied Chemistry, Aston University, Birmingham, B4

$4 \quad 7 \mathrm{ET}, \mathrm{UK}$

$5 \quad$ Email: k.doudin@aston.ac.uk

6

\section{Abstract}

8 Biodiesel is an alternate renewable, biodegradable, non-toxic fuel similar to conventional

9 fossil fuel. It is usually produced from vegetable oil, animal fat, tallow, non-edible plant oil and waste cooking oil. Residue oil components and by-products from the production process or contamination during handling and storage could affect the quality of the biodiesel. The molecular compositions of biodiesel samples have been investigated by a combination of NMR spectroscopic methods. The use of NMR spectroscopy is a novel method to biodiesel characterisation is implemented to fully characterise and assign the molecular structure of biodiesel samples and to identify and quantify the moieties the molecules, particularly the unsaturated long-chain alkyl esters. The NMR spectroscopic method was also implemented to evaluate the transesterification process; the amount of trans-esterified biodiesel in the samples and amounts of un-reacted different types of glycerides. Furthermore, the NMR spectroscopic method is developed to quantify methanol in biodiesel and proposed here as alternative to the official method.

\section{Key words}

Biodiesel; Analysis; Quantification; Characterisation; Transesterification; NMR Methods; 


\section{Introduction}

Biodiesel is a vegetable oil or animal fat-based diesel fuel consisting of long-chain alkyl esters, it is typically formed by the chemical reaction of lipids with alcohol that produce fatty acid esters [1, 2] Biodiesel is renewable, sustainable, biodegradable, non-toxic and clean energy with a good flashpoint, better viscosity and calorific value similar to fossil fuels [3]. It can be used directly in engine in the pure form or as blend with diesel in various proportions to provide alternative solution of fuel in compression ignition engines [4]. The alkyl esters of vegetable oils are produced by a widespread possess known as transesterification; it involves the catalysed reaction of triglycerides (major compounds of oils and fats) and short-chain alcohols such as methanol and ethanol [5]. Most transesterification industrial processes employ alkaline catalysis (potassium or sodium hydroxide) and methanol [6, 7]. The transesterification reaction mixture is also composed of glycerol, excess alcohol, catalyst, unreacted triglycerides and some partially reacted oils (mono and di-glycerides) of fatty acids [6], as well as some free fatty acids [8]. These by-products and other contaminants of biodiesel can lead to severe operational and environmental issues [9]. Therefore, standards that limit the amount of by-products in biodiesel fuel are implemented $[9,10]$. The contaminants from the transesterification reaction are normally monitored during the biodiesel production to recognize and correct problems at an early stage [11]. The free glycerine, catalysts, alcohol, and free fatty acids in the alkyl esters are normally remove at the end of the transesterification process [12]. Other factors such as composition of feedstock can influence biodiesel fuel quality; biodiesel composition is dependent on the source used to produce it [13]. The fatty acids chain length, degree of unsaturation and the presence of other chemical functions have an effect on biodiesel properties, which may influence its storage and oxidation $[6,11,14]$.

The analytical methodologies used to evaluate biodiesel are normally based on gas chromatography (GC) [15, 16], high-performance liquid chromatography (HPLC) [17-19] 
and some spectroscopic analytical methodologies or procedures based on physical properties $[10,20,21]$. In fact, GC has been the most used technique due to its high accuracy for the quantification of minor components. However, baseline drift, overlapping signals, standards are needed and samples can destructively affect the GC accuracy. Moreover, GC analyses frequently require sample derivatisation, mainly to afford trimethylsilyl derivatives of the hydroxyl groups. Flame ionization detection (FID) is the most widespread detector used in GC, but the utilisation of mass spectrometer has increased. The latter eliminates ambiguities about the identification of the eluting materials, but their quantification could be affected. Another drawback of the GC analysis is some components of the biodiesel aren't volatile enough to be evaporated and quantified by the GC analysis $[6,10]$.

HPLC analysis is less employed in biodiesel characterisation; the sample derivatisation is not needed. Moreover, this technique can be applied to biodiesel from different feedstock and a variety of detector can be used, the most commonly used ones are UV/DAD and MS. The two methods, i.e. GC and HPLC are heavily dependent on the use of standards for every component of the biodiesel, hence, chemical changes and the formation of new products during the storage of biodiesel would be difficult to identify by the use of those two methods.

Nuclear magnetic resonance (NMR) spectroscopy and several spectroscopic techniques such as infrared spectroscopy (FTIR) are commonly employed for monitoring the transesterification reaction and for the determination of biodiesel blend levels [22-25]. NMR is an excellent powerful technique, currently underused in biodiesel analysis. I this work, NMR methods were employed to demonstrate the simplicity of using this powerful technique to develop methods to fully identify and quantify the components of biodiesel samples at different stages of their lifetimes, i.e. after transesterification, after purification and after storage or after thermal treatments which might facilitate the production of oxidation and polymerisation transformation products where an NMR methods can be implemented to identify and quantify any formed transformation products. 


\section{Material and methods}

82

83

84

\subsection{Transesterification}

The reaction of transesterification was carried out in a $500 \mathrm{~mL}$ three neck round bottom flask, provided with magnetic stirring, dropping funnel and condensation systems. Biodiesel was produced by transesterification of pure sunflower oil with methanol and catalysed by potassium hydroxide. The procedure followed is described next in the following steps:

1- The reactor was preheated to $65^{\circ} \mathrm{C}$, to eliminate moisture, and then $350 \mathrm{~g}$ ( $\sim 0.4$ mole) of sunflower oil was added. When the reactor reached $65{ }^{\circ} \mathrm{C}$ again, $3.5 \mathrm{~g}$ ( $1 \%$ weight of the oil) potassium hydroxide were dissolved in $100 \mathrm{ml}(\sim 2.4$ mole $)$ methanol, the potassium hydroxide/methanol solution were poured into dropping funnel and gently added dropwise to the stirring oil. The reaction mixture was refluxed for two hours with continues stirring thus the conversion to esters was practically complete.

2- After allowing the reaction mixture cooling down to room temperature, the mixture poured into $1 \mathrm{~L}$ separatory funnel and two formed phases were separated; the upper phase consisted of methyl esters, and the lower phase contained the glycerol, the excess methanol, the remaining catalyst together with the soaps formed during the reaction, and some entrained methyl esters and partial glycerides.

3- The remaining catalyst was extracted by successive rinses with distilled water and separating the two layers by sedimentation overnight.

4- The methyl esters were further purified by distilling the residual water and methanol at $80{ }^{\circ} \mathrm{C}$ under reduced pressure in rotary evaporator for one hour.

5- After cooling to room temperature, the Biodiesel transferred into plastic bottle and stored closed in dark at room temperature. 
Nuclear magnetic resonance spectra were recorded on a Bruker Avance-300 spectrometer at ambient temperature using a $5 \mathrm{~mm}$ high-resolution dual $\left({ }^{1} \mathrm{H}^{13} \mathrm{C}\right)$ gradients probe. The NMR samples were prepared by dissolving $50 \mathrm{mg}$ of the biodiesel samples in $0.7 \mathrm{ml}$ deuterated chloroform $\left(\mathrm{CDCl}_{3}\right)$ solvent which contained $0.05 \%$ TMS. The Biodiesel samples for the NMR analysis were taken at the following points:

- The sample of pure biodiesel was taken at the end of step 5 of Section 2.1.

- The sample containing some methanol was taken at the end of step 3 of Section 2.1.

- $\quad$ The sample containing some glycerides was taken at the end of step 2 of Section 2.1.

The ${ }^{1} \mathrm{H}$ NMR spectra were recorded at $300 \mathrm{MHz}$ using the zg30 pulse program with 32 scans and referenced to the TMS standard at $0.0 \mathrm{ppm}$. PENDANT ${ }^{13} \mathrm{C}$ NMR spectra were obtained at $75 \mathrm{MHz}$ for carbon. The pendant pulse program was used with waltz16 decoupling during acquisition with 2048 scans and phased for $\mathrm{CH}_{3} / \mathrm{CH}$ positive and quaternary carbons and $\mathrm{CH}_{2}$ negative and referenced to the TMS standard at $0.0 \mathrm{ppm}$. The 2-Dimensional ${ }^{1} \mathrm{H}-{ }^{13} \mathrm{C}$ Heteronuclear Single Quantum Coherence (HSQC) spectra, which correlate ${ }^{1} \mathrm{H}$ and ${ }^{13} \mathrm{C}$ chemical shifts through single-bond heteronuclear scalar coupling $\left({ }^{1} \mathrm{~J}_{\mathrm{CH}}\right)$ were also recorded. The cross peaks in the ${ }^{1} \mathrm{H}_{-}{ }^{13} \mathrm{C}$ HMBC spectra shows the chemical shifts of ${ }^{1} \mathrm{H}$ on one axis (horizontal) which correlated to ${ }^{13} \mathrm{C}$ (on the vertical axis) that belongs to $\mathrm{H}$ and $\mathrm{C}$ atoms which are chemically bonded. 2-Dimensional ${ }^{1} \mathrm{H}_{-}{ }^{13} \mathrm{C}$ Heteronuclear Multiple Bond Coherence (HMBC) spectra, which correlate ${ }^{1} \mathrm{H}$ and ${ }^{13} \mathrm{C}$ chemical shifts through multiplebond heteronuclear scalar coupling $\left({ }^{\mathrm{n}} \mathrm{J}_{\mathrm{CH}}, \mathrm{n}=2\right.$ or 3$)$ were also recorded. The cross peaks in the ${ }^{1} \mathrm{H}-{ }^{13} \mathrm{C}$ HMBC spectra shows the chemical shifts of ${ }^{1} \mathrm{H}$ on one axis (horizontal) which 
127 correlated to ${ }^{13} \mathrm{C}$ (on the vertical axis) that belongs to $\mathrm{H}$ and $\mathrm{C}$ atoms which are separated by two or three chemical bonds.

\section{Results and discussion}

\subsection{Characterisation of Biodiesel}

131

A ${ }^{1} \mathrm{H}$ NMR spectrum of a biodiesel sample used in this work is shown in Figure 1 together with the structures of three methyl esters; mono and two di-unsaturated fatty groups (conjugated and non-conjugated), the main signals are labelled; signal (A) is for the hydrogens of unsaturated moieties $-\mathrm{CH}=\mathrm{CH}-$ from both isolated and non-conjugated double bonds and also for the two outer hydrogens $(-\mathrm{CH}=\mathrm{CH}-\mathrm{CH}=\mathrm{CH}-)$ of the conjugated double bonds at $5.31 \mathrm{ppm}$, the signal (A') is for the inter hydrogens $(-\mathrm{CH}=\mathrm{CH}-\mathrm{CH}=\mathrm{CH}-)$ of the conjugated double bonds at about $6 \mathrm{ppm}$. The signal $(\mathrm{C})$ is for the methylene $-\mathrm{CH}_{2}-$ between two non-conjugated double bonds at $2.74 \mathrm{ppm}$, the signal (E) at $2.01 \mathrm{ppm}$ is for the $\mathrm{CH}_{2}-$ adjacent to the double bonds is an important signal to be used to probe the differences in the double bond molecules, the signal (D) at $2.27 \mathrm{ppm}$ is for the $-\mathrm{CH}_{2}-$ adjacent to the carbonyl group which is used as internal reference to relatively quantify the other groups in the biodiesel molecules, the signals $(\mathrm{G})$ at 1.6 and $1.28 \mathrm{ppm}$ are for the aliphatic $-\mathrm{CH}_{2}-$; their chemical shifts are unaffected by nether of the ester group nor the double bonds. The end of chain aliphatic $-\mathrm{CH}_{3}$ (signal $\mathrm{W}$ ) is at $0.86 \mathrm{ppm}$ and the methyl ester $-\mathrm{CH}_{3}$ (signal B) is at $3.63 \mathrm{ppm}$. The following table (Table 1) summarises the signals and their chemical shifts.

Table 1: Biodiesel different molecule moieties and their ${ }^{1} \mathrm{H}$ NMR chemical shifts are summarised.

\begin{tabular}{|l|l|l|l|}
\hline Signal & moietie & chemical shifts ppm & \\
\hline A & $\begin{array}{l}-\mathrm{CH}=\mathrm{CH}- \\
(-\mathrm{CH}=\mathrm{CH}-\mathrm{CH}=\mathrm{CH}-)\end{array}$ & $5.31 \mathrm{ppm}$ & \\
\hline $\mathrm{A}^{\prime}$ & $(-\mathrm{CH}=\mathrm{CH}-\mathrm{CH}=\mathrm{CH}-)$ & at about $6 \mathrm{ppm}$ & \\
\hline B & methyl ester $-\mathrm{CH}_{3}$ & $3.63 \mathrm{ppm}$ & \\
\hline C & $-\mathrm{CH}_{2}-$ between two non-conjugated double & $2.74 \mathrm{ppm}$ & \\
\hline
\end{tabular}




\begin{tabular}{|l|l|l|l|}
\hline $\mathrm{D}$ & $-\mathrm{CH}_{2}-$ adjacent to the carbonyl group & $2.27 \mathrm{ppm}$ & \\
\hline $\mathrm{E}$ & $-\mathrm{CH}_{2}-$ adjacent to the double bonds & $2.01 \mathrm{ppm}$ & \\
\hline $\mathrm{G}$ & The aliphatic $-\mathrm{CH}_{2}-\mathrm{s} ;$ & 1.6 and $1.28 \mathrm{ppm}$ & \\
\hline$W$ & End of chain aliphatic $-\mathrm{CH}_{3}$ & $0.86 \mathrm{ppm}$ & \\
\hline
\end{tabular}

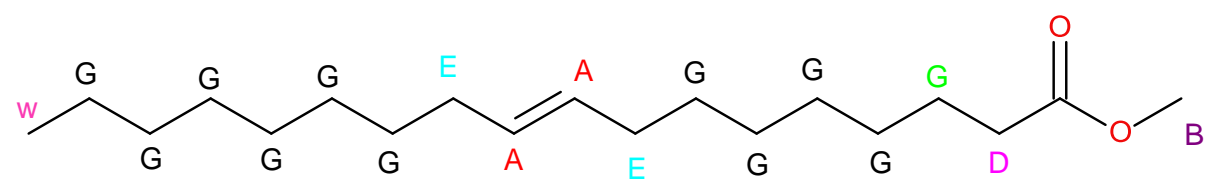<smiles>[B]CCCCC=CCC=CCCCCCCCCC(=O)OC</smiles>

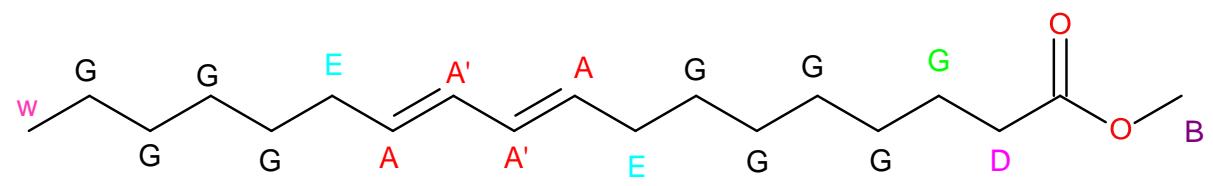

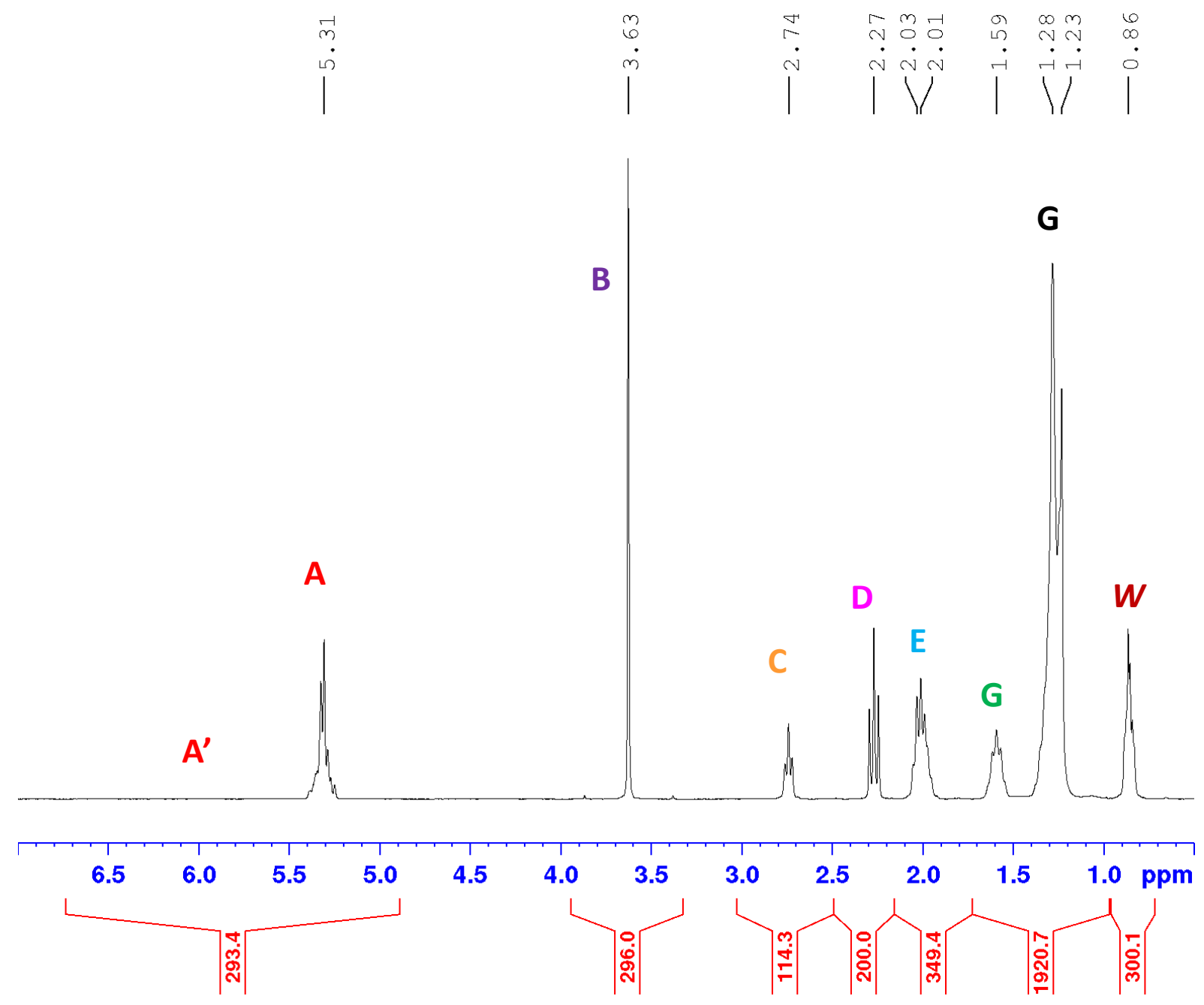

151 Figure 1: a typical ${ }^{1} \mathrm{H}$ NMR spectrum of biodiesel with labelling/assignment of the major 152 peaks 
$154 \quad \mathrm{~A}^{13} \mathrm{C}$ Pendant NMR spectrum of biodiesel with labelled signals is shown on Figure 2, The 155 signal for the carbonyl carbon (-COO-) is at $174.0 \mathrm{ppm}$, the signals for the unsaturated ($156 \mathbf{C H}=\mathbf{C H}-)$ carbons and the outer carbons of the nun-conjugated

$157 \mathrm{CH}=\mathrm{CH}-)$ are at $129.8 \mathrm{ppm}$ and the inner carbons of the nun-conjugated $\left(-\mathrm{CH}=\mathrm{CH}-\mathrm{CH}_{2}-\right.$ $158 \mathrm{CH}=\mathrm{CH}-)$ are at $127.9 \mathrm{ppm}$, the signal for the methyl ester carbon $\left(-\mathrm{O}-\mathrm{CH}_{3}\right)$ is a $51.2 \mathrm{ppm}$, the signals for the carbons of the aliphatic methylene $\left(-\mathrm{CH}_{2}-\mathrm{s}\right)$ are in the region of 34 to 27 ppm, and the signal for the end chain methyl $\left(-\mathrm{CH}_{3}\right)$ carbon is at $13.9 \mathrm{ppm}$.
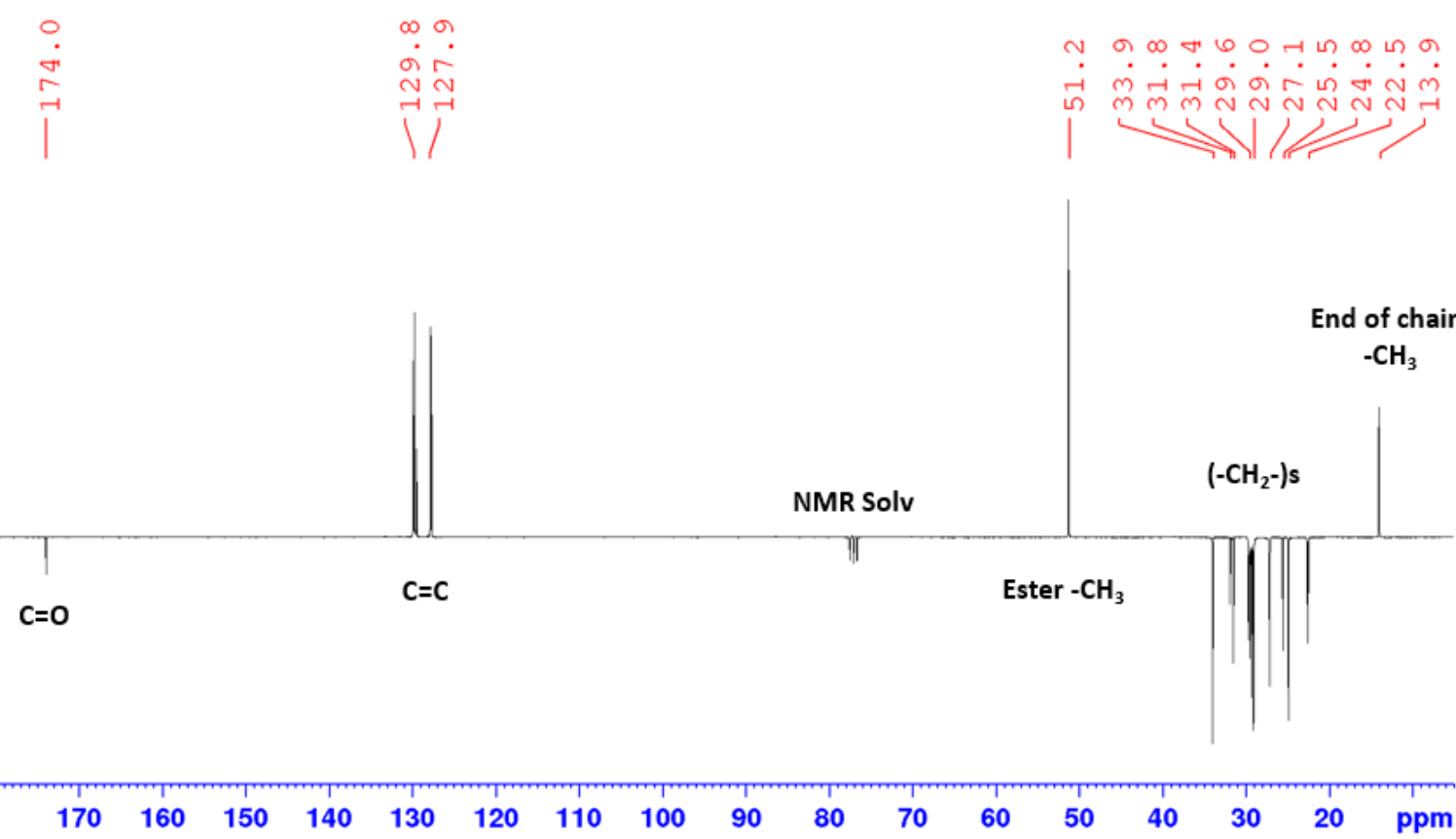

Figure 2: a typical ${ }^{13} \mathrm{C}$ (PENDANT) NMR spectrum of biodiesel with labelling/assignment of the major peaks.

166 The assignment of the ${ }^{1} \mathrm{H}$ and ${ }^{13} \mathrm{C}$ NMR spectral signals is confirmed by spectral analysis of 167 single bond carbon hydrogen couplings from 2D ${ }^{1} \mathrm{H}-{ }^{13} \mathrm{C}$ HSQC NMR spectrum of the 
168 Biodiesel, see Figure 3. The two-dimensional (2D) spectrum with one axis for hydrogen $\left({ }^{1} \mathrm{H}\right)$

169 NMR and the other for carbon $\left({ }^{13} \mathrm{C}\right) \mathrm{NMR}$, it contains a peak (contour plot) for each unique 170 hydrogen attached with a single bond to the carbon being considered. The assignment of 171 three example peaks are indicated with different doted colour lines on Figure 3; the signal (C) 172 for the $-\mathrm{CH}_{2}-$ between two non-conjugated double bond at $2.74 \mathrm{ppm}$ is correlating to its carbon at $25.5 \mathrm{ppm}$, the signal (E) at $2.01 \mathrm{ppm}$ for the $-\mathrm{CH}_{2}-$ adjacent to the double bonds is 174 correlating to its carbon at $27.0 \mathrm{ppm}$, and the signal (D) at $2.27 \mathrm{ppm}$ for the $-\mathrm{CH}_{2}-$ adjacent to the carbonyl group is correlating to its carbon at $33.9 \mathrm{ppm}$. Also the signal (A) for the unsaturated $-\mathbf{C H}=\mathrm{CH}-$ from double bonds at $5.31 \mathrm{ppm}$ is correlating to the two carbon peaks at about 127.9 and $129.8 \mathrm{ppm}$ (not shown in the Figure). Other hydrogen signals are also correlating to their carbon signals as shown on Figure 3.

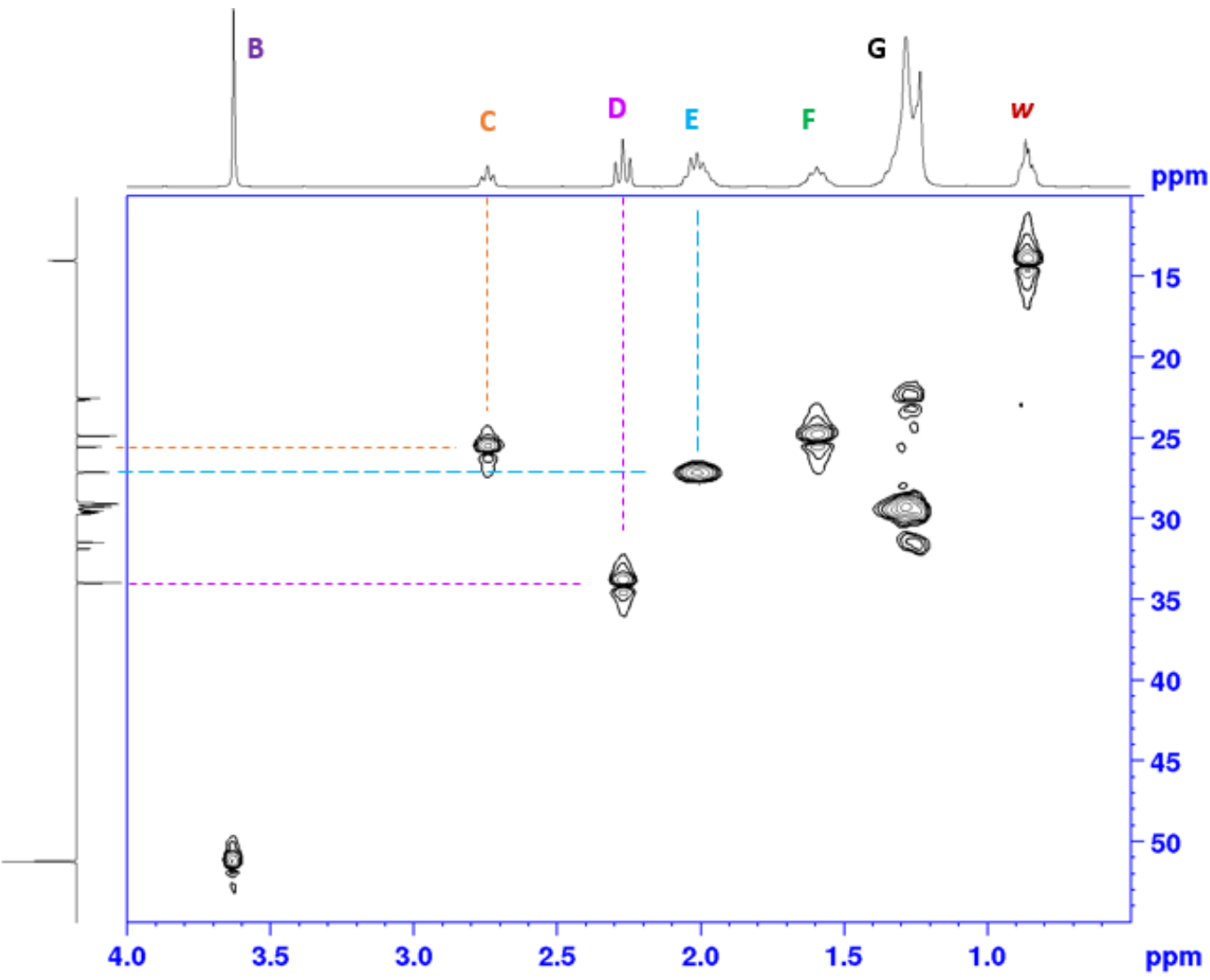
major peaks. 
183 The assignment of the signals are further confirmed by another 2D NMR analysis, the use of 184 long range carbon hydrogen couplings, a $2 \mathrm{D}{ }^{1} \mathrm{H}_{-}{ }^{13} \mathrm{C}$ HMBC spectrum of the biodiesel sample 185 is shown on Figure 4, the contour plots showing the correlation between the hydrogen peaks 186 and the peaks of the carbons which are two or three bonds away from the hydrogen in 187 question. As an example; the carbonyl carbon at 174ppm has correlations with its three neighbouring Hs (red dotted line); the methyl ester (peak B at $3.63 \mathrm{ppm}$ ), the methylene group adjacent to the carbonyl group (peak D at $2.72 \mathrm{ppm}$ ) and the second methylene group in the chain (peak F at $1.59 \mathrm{ppm}$ ). The double bond carbon at $129 \mathrm{ppm}$ has correlations to the 191 hydrogen on the other carbon double bond atom, to the hydrogens of the methylene group 192 between the double bonds (peak C) and to the hydrogens of the adjacent to the double bonds 193 (peak E) and also another weaker correlation to a second methylene from group E.

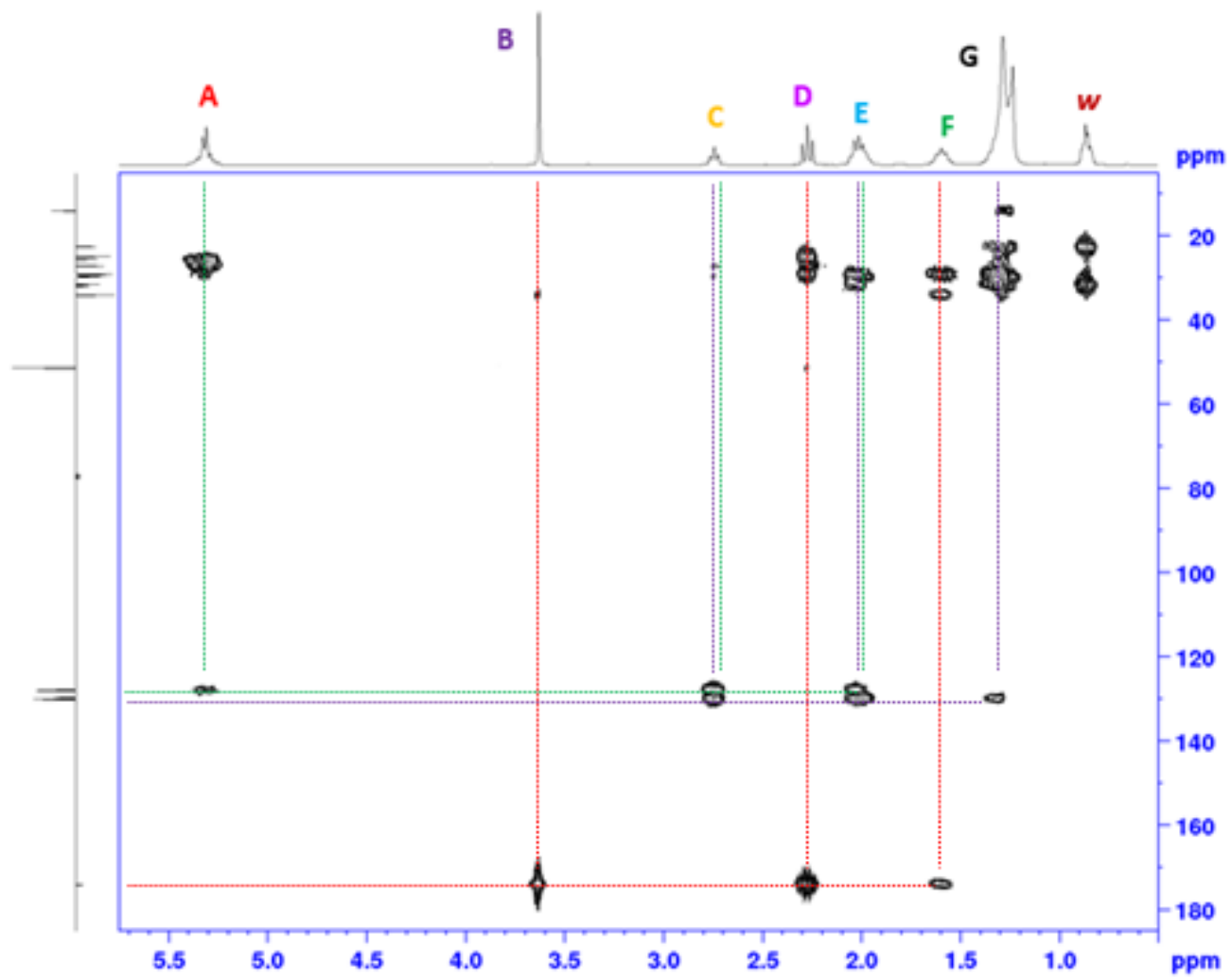


Figure 4: 2D ${ }^{1} \mathrm{H}_{-}{ }^{13} \mathrm{C}$ HMBC NMR spectrum of biodiesel with labelling/assignment of the major peaks.

\subsection{Quantification of Biodiesel}

The integrals of the ${ }^{1} \mathrm{H}$ NMR signals are used to quantify the amount of the different molecular moieties (functional groups) of biodiesel samples, i.e. isolated, conjugated and non-conjugated double bonds, carbonyl groups, aliphatic methylene groups, end of chain methyl group and methyl ester group. The integral (peak area) of the signals quantifies the relative numbers of hydrogens in the targeted group, the integrals of the different groups are referenced to a stable group and hence the signal of a stable group is used as internal standard.

The amounts of the carbonyl groups in the samples are quantified using the $-\mathbf{C H}_{2}$ - methyl group adjacent to the carbonyl group which has a chemical shift of $2.27 \mathrm{ppm}$. This peak at $2.27 \mathrm{ppm}$ (D) is also used as an internal reference, it is integrated for 2 hydrogens per a biodiesel molecule, if this group does not exist, the molecule would not be a biodiesel one (without the carbonyl group, the molecule would be aliphatic hydrocarbon), therefore, it is used as internal reference. For simplicity, the quantitation is conducted in a 100 molecules, and hence, the integral for the peak at $2.27 \mathrm{ppm}$ is set to 200 in Figure 1, as there are 200 hydrogens of such a type in a 100 molecules of Biodiesel. Also working on 100 molecule bases allows the direct convention of the amounts of the different groups into percentages.

\subsection{Total double bonds}

The peak at $5.31 \mathrm{ppm}(\mathrm{A})$ in Figure 1, is the signal for the $-\mathrm{CH}=\mathrm{CH}$ - double bonds which is integrated for 2 hydrogens per each double bond group, the signal integral is used to quantify the amount of double bonds in a 100 molecules of Biodiesel molecules. In the given example in Figure 1, the integral of the peak at $5.31 \mathrm{ppm}$ is 293.4 , dividing that by the number of 
hydrogens in each double bond which is 2 , gave a 146.7 as the total number of double bonds in a 100 molecules of Biodiesel.

The peak at $2.0 \mathrm{ppm}(\mathrm{E})$ in Figure 1, is for the $-\mathrm{CH}_{2}$ - surrounding the double bonds which is also integrated for 2 hydrogens per each group; there are two of such a group in every molecule which have any type of double bond systems (isolated, conjugated or nonconjugated double bonds), hence there are 4 hydrogens in each molecule. The integral for this signal is used quantify the number of the molecules which have any type of double bonds in the 100 Biodiesel molecules. In the given example in Figure 1, the area of the peak at 2.0 ppm is 349.4 dividing that by the number of hydrogens [4], gave 87.4 , which is the total number of molecules have double bonds in a 100 molecules of Biodiesel, i.e. $87.4 \%$ of the Biodiesel molecules contain a type of double bonds.

The allylic hydrogens peak at $2.74 \mathrm{ppm}(\mathrm{C})$ for the $-\mathrm{CH}_{2}$ - between two double bonds which has 2 hydrogens per every non-conjugated group. The integral of this peak is used to quantify the amounts of non-conjugated molecules in the biodiesel. In the given example in Figure 1, the area of the peak at $2.74 \mathrm{ppm}$ is 114.3 dividing that by the number of hydrogens in that group which is 2 , gave 57.2. The 57.2 is the number of non-conjugated molecules in a 100 molecules of Biodiesel, in other words, $57.2 \%$ of the fatty groups in this biodiesel are nonconjugated which are normally referred to as $\mathrm{C} 18: 2$ in the literature [26] and that is the expected value of C18:2 in sunflower oil which was used to produce the biodiesel samples analysed here [27]. Since every non-conjugated molecule has two double bonds, therefore, the number of the double bonds in the non-conjugated molecules is 114.3 bonds.

The amount of the remaining double bonds which are within the peak at $5.31 \mathrm{ppm}$, they are either mono-unsaturated or the outer hydrogens of the conjugated double bond systems and they can be quantified from the difference between the above values. In the given example, the amount of the total double bonds is 146.7 , form these there are 114.3 double bonds in 
57.2 non-conjugated molecules, the remaining are 32.4 double bonds $(146.7-114.3=32.4)$, they are either in mono-unsaturated or conjugated double bond molecules.

Subtracting the non-conjugated molecule (57.2 molecules) from the total number of molecules that have double bonds ( 87.4 molecules), that give a value of 30.2 which is the amount of the mono-unsaturated and conjugated molecules.

The amounts of the conjugated molecules (x) and the mono-unsaturated molecules (y), there are 30.2 molecules in the two systems, hence,

$\mathrm{x}+\mathrm{y}=30.2-\cdots($ eq 1$)$

There are two double bond in every conjugated molecule and only one double bond in every mono-unsaturated molecule, both systems have a total of 32.4 double bonds,

$$
2 x+y=32.4-\cdots(\text { eq } 2)
$$

Solving the above two equations gave amount of the mono-unsaturated as 28 molecules and the amount of conjugated molecule as 2.2 molecules. If the remaining molecules are saturated ones, then there would 12.6 (100 - 87.4 molecules) of that type in the 100 molecules of Biodiesel

The aliphatic methylene $-\mathrm{CH}_{2}$ - group has peaks at 1.6 and $1.2 \mathrm{ppm}$, the peak at $1.6 \mathrm{ppm}$ is mainly for the hydrogens on the carbon number 3 in the aliphatic fatty chain. The other peak at $\sim 1.2 \mathrm{ppm}$ which is for the other $\mathrm{G}$ of $-\mathrm{CH}_{2}$-s groups, they all have an integral value of 1923, which indicate that there is that many hydrogens in such an environment in 100 molecules of the biodiesel. In a $\mathrm{C} 18: 2$ non conjugated molecule there are $8-\mathrm{CH}_{2}$-s of type $\mathrm{G}$ (as shown on structure drown Figure 1), it is calculated above, the amount of the nonconjugated molecules in the used example are 57.2 molecules, therefore, they would have 8 (number of $\mathrm{CH}_{2} \mathrm{~S} \times 56.4$ (number of molecules) x 2 (number of hydrogens in a $\mathrm{CH}_{2}$ ) $=915$ hydrogens. Similarly there are 28 molecules of mono unsaturated, in each mono unsaturated 
molecule there is 11 methylene of type $\mathrm{G}$, and they contain $11 \times 28 \times 2=616$ hydrogens. In the $\mathrm{C} 18: 2$ conjugated molecules there are $9 \mathrm{G}$ groups in each and 2.2 molecules there are 40 hydrogens $9 \times 1.1 \times 2=39.6$. It is known that the saturated fatty groups in sunflower oil are about 2:1 C16:C18 [27], hence in the 12.6 molecules of saturated C16:C18 fatty acids, 272 there are 13 or 15 methylene of type $G$ in each molecule; which mean there are $(13 \times 8.4 \times 2)$ $273+(15 \times 3.8 \times 2)=332$, also there is about 12 hydrogens in other low amounts of $\mathrm{C} 14: 0$ and $274 \mathrm{C} 20: 0,0.1$ and $0.3 \%$, respectively, therefore, the amounts of hydrogens in saturated molecules is 344 .

In total there are $(915+616+40+332+12)=1915$ hydrogens for group $\mathrm{G}$ methylene types, which is very close to the 1921 integral of that peak. The number of counted hydrogen is slightly smaller than the integral value which could be explained as there are some low concentration molecules not accounted for here such as C12:0 and C18:3.

The peak at $3.63 \mathrm{ppm}$ is for the methyl ester $-\mathrm{CH}_{3}$, in a $100 \%$ trans-esterified sample, this peak should have an integral of 300 , as there would 300 hydrogens in in such a type (type B) in 100 molecules of the biodiesel. In the analysed sample shown in Figure 1, the integral for the peak at $3.63 \mathrm{ppm}$ in 296 which mean the amount of the methyl esterification in the sample is $98.7 \%(296 / 3)$.

In summery there are 146.7 double bonds in a 100 molecules of biodiesel, that number of double bonds is in 87.4 molecule, from those molecules there 57.2 non-conjugated C18:2 molecules, 2.2 conjugated $\mathrm{C} 18: 2$ molecule and 28 mono-unsaturated $\mathrm{C} 18: 1$ molecules. Also the amount of the trans-esterified molecules in the sample is $98.7 \%$. The results and the indication how each value is calculated is presented in Table 2. 
295 Table 2: summery of the calculated components of the analysed biodiesel sample.

\begin{tabular}{|l|l|l|l|}
\hline Group & Used method & $\begin{array}{l}\text { Double bonds } \\
\text { No. }\end{array}$ & Molecule amounts \\
\hline Total number double bonds & Pear 5.31 ppm & 146.7 bonds & \\
\hline $\begin{array}{l}\text { Number of molecules with } \\
\text { double bonds }\end{array}$ & Peak 2.0 ppm & & 87.4 molecule \\
\hline non-conjugated molecules & Peak 2.74 ppm & 114.3 bonds & 57.2 molecule \\
\hline Mono \& conjugated bonds & $\begin{array}{l}146.7-114.3= \\
32.4\end{array}$ & 32.4 bonds & \\
\hline $\begin{array}{l}\text { Mono \& conjugated } \\
\text { molecules }\end{array}$ & $87.4-57.2=$ & & 30.2 molecule \\
\hline Mono-unsaturated & 30.2 & 28 bonds & 28 molecule \\
\hline conjugated & & 4.4 bonds & 2.2 molecule \\
\hline saturated & $100-87.4=12.6$ & & 12.6 molecule \\
\hline Methyl esterified molecules & Peak 3.63 ppm & & 98.7 molecule \\
\hline
\end{tabular}

\subsection{Quantification of Free methanol in Biodiesel}

The free methanol has its $-\mathrm{CH}_{3}$ peak at $3.45 \mathrm{ppm}$ in the ${ }^{1} \mathrm{H} \mathrm{NMR}$, the sample presented in Figure 5 contain some menthol, and this peak can be used to quantify the amount of free methanol in biodiesel sample. The integral of the signal divided the number of the hydrogens for that particular signal is equivalent to their molar percentage compared to biodiesel. In the sample presented in Figure 5 for every 100 molecules of Biodiesel there is 23 molecules of methanol; based on keeping the integral of the peak at $2.27 \mathrm{ppm}$ at value of 200 for a 100 biodiesel molecules, the methanol peak has integral value of 68.8 , dividing that integral value by the number of hydrogens [3] in the methyl group. The 23 methanol molecules for every 100 biodiesel molecules are equivalent to their molar ratios. The molar ration can be converted to weight percentage of the methanol in the sample by multiplying each by its molecular weight which gives a weight ratio of $100 \times 296: 23 \times 32=29600: 736$ or 40:1 which mean there is $2.43 \mathrm{w} \%$ methanol in this particular sample (by normalising to $100 \%$ ). 


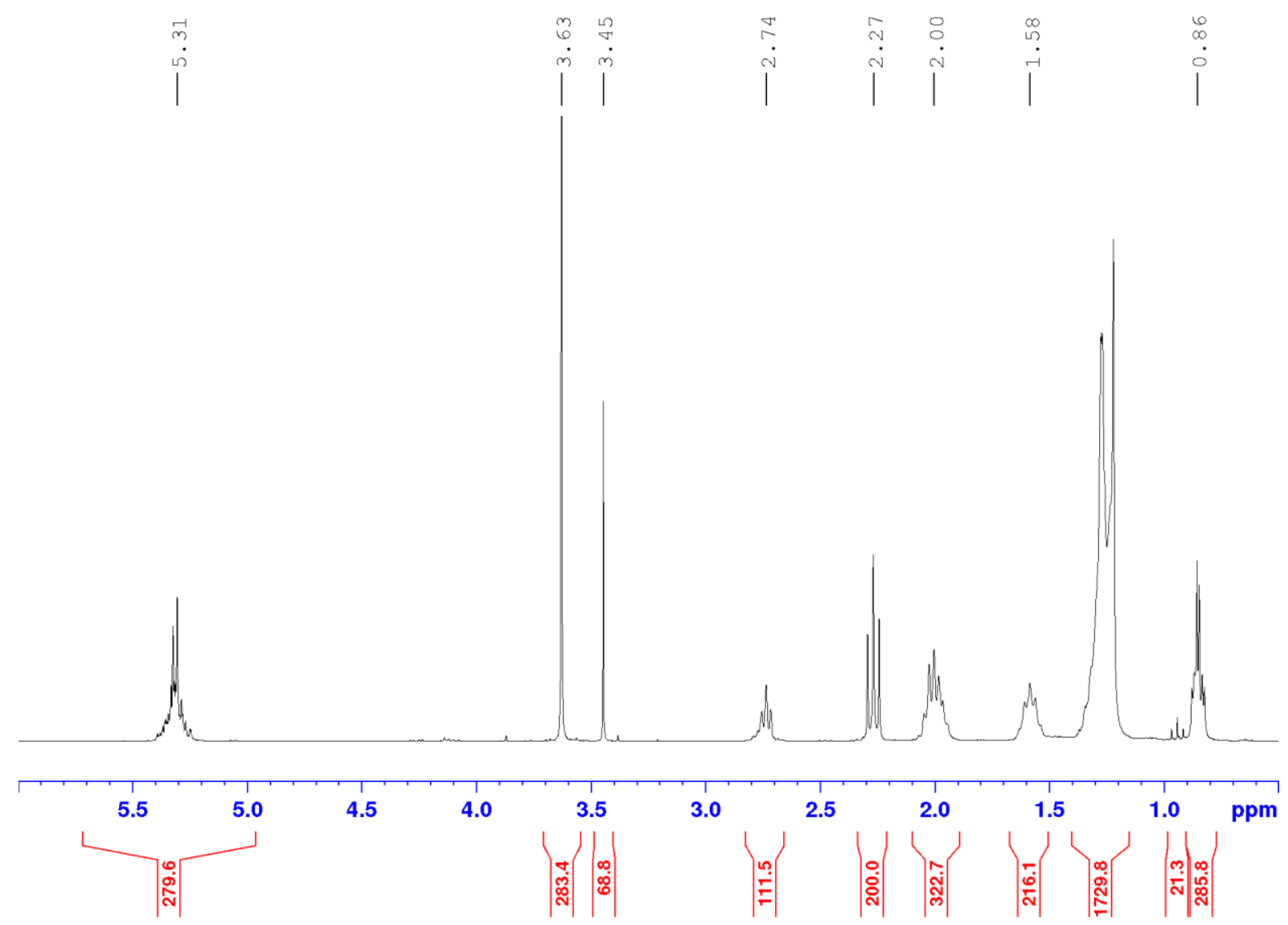

313 Figure 5: ${ }^{1} \mathrm{H}$ NMR spectrum of a biodiesel sample contain some methanol, the methanol peak 314 is at $3.45 \mathrm{ppm}$.

$316 \quad 3.5 \quad$ Quantification of Glycerol, mono-, Di and tri-glyceride in Biodiesel

317 In the ${ }^{1} \mathrm{H}$ NMR spectrum shown in Figure 6, the glycerol moiety in triglycerides has two 318 double of doublet peaks around $4.2 \mathrm{ppm}$ (4.15 and $4.3 \mathrm{ppm}$, blue spectra). Also the main 319 peaks for a glycerol moiety in the di-glycerides (1,3-dilinolein) is at about $4.15 \mathrm{ppm}$ (red spectra). The glycerol peaks of di-glycerides are at a similar chemical shift to the right hand

321 side part of the peak observed for the triglycerides. In the 1-monolinolein (mono-glycerides)

322 sample, the peak of the glycerol number one $-\mathrm{CH}_{2}$ - moieties is also appearing symmetrical at 
the $4.15 \mathrm{ppm}$ chemical shift (green spectra). The other peaks are appearing at about $3.6 \mathrm{ppm}$

324 in the 1-monolinolein sample associated with the $-\mathrm{CH}_{2}$ - number three of glycerol moiety and

325 the peak at $3.93 \mathrm{ppm}$ is due to the $-\mathrm{CH}$ - number two of the mono-glyceride [28].

326 As shown here, the three types of glycerides has peaks at $4.15 \mathrm{ppm}$, only triglyceride should

327 have the other peak at $4.3 \mathrm{ppm}$, hence this peak can be used to quantify the amount of tri-

328 glycerides in biodiesel.

329 In the given example on Figure 6, the integral value of the peak at $4.15 \mathrm{ppm}$ is 8.16 , 330 implementing similar methods as the above; in every 100 molecules of biodiesel there is 4.08

$331(8.16 / 2=4.08)$ molecules of triglycerides in the analysed sample in the given example in 332 Figure 6. As there are three fatty acids in every molecule of triglycerides, which is about $33312.24 \%$ oil in the analysed biodiesel sample.

334 The deference in the integral value of the two peaks at 4.15 and $4.3 \mathrm{ppm}$ and the peak at 335 3.93ppm can be used to quantify the amount of mono- and di-glycerides in biodiesel, the remaining value of 2.3 (from 10.5-8.16) contains four hydrogens of the di-glycerides and two hydrogens from mono-glyceride. The peak at $3.93 \mathrm{ppm}$ which is for the central one hydrogens of mono-glyceride, so that can be used first to quantify the mono-glyceride and the remaining about of glycerol would be from the di-glyceride. 


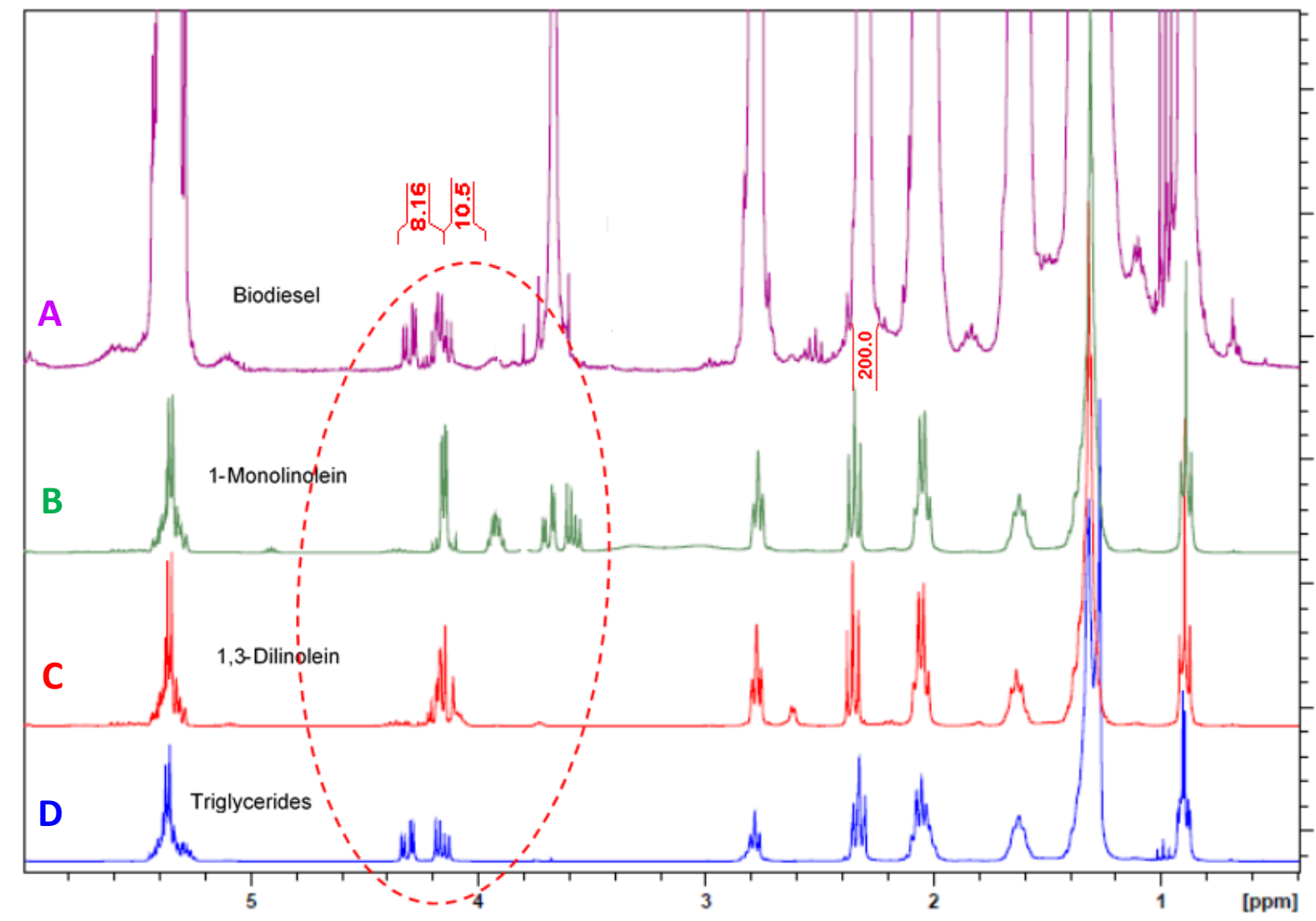

341 Figure 6: ${ }^{1} \mathrm{H}$ NMR spectra of biodiesel (A), mono- Di- and tri-glycerides (B, C \& D

342 respectively), with the glycerol peaks circulated with the red oval dashed line. 
The results demonstrate adequate performance of the 1H NMR methods for the successful characterisation and identification the molecular structure of biodiesel sample components, using ${ }^{1} \mathrm{H}$ NMR, ${ }^{13} \mathrm{C}$ Pendant NMR and two 2D ${ }^{1} \mathrm{H}_{-}{ }^{13} \mathrm{C}$ NMRs; HSQC and HMBC. Furthermore, the presented results demonstrate the successful use of the ${ }^{1} \mathrm{H}$ NMR method for the quantification of the identified components and the amounts of the different molecules moieties in biodiesel molecules. Also the presented work demonstrated the used the ${ }^{1} \mathrm{H}$ NMR method to follow the transesterification process and the evaluation of the remaining unreacted glycerides, and the free fatty acids in Biodiesel samples. The NMR method was also employed to quantify the amounts of the free alcohols in biodiesel samples. Based on the above considerations, the studied NMR methods can be suggested as stand-alone alternative methods without the need for standards or derivatization to characterise to study the unsaturated systems of the alkyl chain, the length chain and the quantification of glycerides samples based on NMR spectroscopy. 
1. Canakci M, Sanli H. Biodiesel production from various feedstocks and their effects on the fuel properties. J Ind Microbiol Biotechnol. 2008;35(5):431-41.

$380 \quad 2 . \quad$ Advanced Renewable Energy Systems. Bhatia SC, editor2014.

381 3. Li C, Lesnik K, Liu H. Microbial Conversion of Waste Glycerol from Biodiesel Production into Value-Added Products. Energies. 2013;6(9):4739-68. feedstocks, production processes, and yield for different generations of biodiesel. Fuel. 2020;262.

5. Gebremariam SN, Marchetti JM. Biodiesel production technologies: review. Aims Energy. 2017;5(3):425-57. . Pint AC, Guarieiro LLN, Rezende MJC, Ribeiro NM, Torres EA, Lopes WA, et al. Biodiesel: an overview. Journal of the Brazilian Chemical Society. 2005;16(6b):1313-30.

7. Ayoob AK, Fadhil AB. Valorization of waste tires in the synthesis of an effective carbon based catalyst for biodiesel production from a mixture of non-edible oils. Fuel. 2020;264.

8. Das S, Thakur AJ, Deka D. Two-stage conversion of high free fatty acid Jatropha curcas oil to biodiesel using Bronsted acidic ionic liquid and $\mathrm{KOH}$ as catalysts. Scientific World Journal. 2014; 180983.

9. Monteiro MR, Ambrozin ARP, Liao LM, Ferreira AG. Critical review on analytical methods for biodiesel characterization. Talanta. 2008;77(2):593-605.

10. Knothe G. Analytical methods used in the production and fuel quality assessment of biodiesel. T Asae. 2001;44(2):193-200.

11. Knothe G. Analyzing biodiesel: Standards and other methods. J Am Oil Chem Soc. 2006;83(10):823-33.

12. Atadashi IM. Purification of crude biodiesel using dry washing and membrane technologies. Alex Eng J. 2015;54(4):1265-72.

13. Stauffer E, Byron D. Alternative fuels in fire debris analysis: biodiesel basics. J Forensic Sci. 2007;52(2):371-9.

14. Mantovani ACG, Chendynski LT, Galvan D, de Macedo Júnior FC, Borsato D, Di Mauro E. Thermal-oxidation study of biodiesel by proton nuclear magnetic Resonance $(1 \mathrm{H}$ NMR). Fuel. 2020;274:117833.

15. Pauls RE. A review of chromatographic characterization techniques for biodiesel and biodiesel blends. J Chromatogr Sci. 2011;49(5):384-96.

16. Kaisan MU, Abubakar S, Ashok B, Balasubramanian D, Narayan S, Grujic I, et al. Comparative analyses of biodiesel produced from jatropha and neem seed oil using a gas chromatography-mass spectroscopy technique. Biofuels. 2018:1-12.

17. Syed MB. Analysis of biodiesel by high performance liquid chromatography using refractive index detector. MethodsX. 2017;4:256-9.

18. Allen SJ, Ott LS. HPLC method for rapidly following biodiesel fuel transesterification reaction progress using a core-shell column. Anal Bioanal Chem. 2012;404(1):267-72.

19. de Matos TS, dos Santos RC, de Souza CG, de Carvalho RC, de Andrade DF, D'ávila LA. Determination of the Biodiesel Content on Biodiesel/Diesel Blends and Their Adulteration with Vegetable Oil by High-Performance Liquid Chromatography. Energy \& Fuels. 2019;33(11):11310-7. 
423 20. Naureen R, Tariq M, Yusoff I, Chowdhury AJ, Ashraf MA. Synthesis, spectroscopic 424 and chromatographic studies of sunflower oil biodiesel using optimized base catalyzed 425 methanolysis. Saudi J Biol Sci. 2015;22(3):332-9.

426 21. Zhang W-B. Review on analysis of biodiesel with infrared spectroscopy. Renewable 427 and Sustainable Energy Reviews. 2012;16(8):6048-58.

428 22. Knothe G. Determining the blend level of mixtures of biodiesel with conventional 429 diesel fuel by fiber-optic near-infrared spectroscopy and $1 \mathrm{H}$ nuclear magnetic resonance 430 spectroscopy. Journal of the American Oil Chemists' Society. 2001;78(10):1025-8.

431 23. Portela NA, Oliveira ECS, Neto AC, Rodrigues RRT, Silva SRC, Castro EVR, et al. 432 Quantification of biodiesel in petroleum diesel by 1H NMR: Evaluation of univariate and 433 multivariate approaches. Fuel. 2016;166:12-8.

434 24. $\mathrm{Ng} \mathrm{MH}$, Yung CL. Nuclear magnetic resonance spectroscopic characterisation of 435 palm biodiesel and its blends. Fuel. 2019;257:116008.

436 25. Shimamoto GG, Bianchessi LF, Tubino M. Alternative method to quantify biodiesel 437 and vegetable oil in diesel-biodiesel blends through (1)H NMR spectroscopy. Talanta. $438 \quad 2017 ; 168: 121-5$.

439 26. Philippaerts A, Jacobs P, Sels B. Catalytic Hydrogenation of Vegetable Oils. In: 440 Rinaldi R, editor. atalytic Hydrogenation for Biomass Valorization 2014. p. 223-41.

441 27. Orsavova J, Misurcova L, Ambrozova JV, Vicha R, Mlcek J. Fatty Acids 442 Composition of Vegetable Oils and Its Contribution to Dietary Energy Intake and 443 Dependence of Cardiovascular Mortality on Dietary Intake of Fatty Acids. Int J Mol Sci. 444 2015;16(6):12871-90.

445 28. Nieva-Echevarria B, Goicoechea E, Manzanos MJ, Guillen MD. Usefulness of (1)H 446 NMR in assessing the extent of lipid digestion. Food Chem. 2015;179:182-90. 